INTRA-CAPSULAR EXPRESSION OF CATARACT

BY

C. V. Krishnaswami, M.B., B.S.(Madr.),
D.O.M.S.(Lond.), F.R.C.S.E.

MADRAS

\title{
Introduction
}

To the ophthalmologist all the world over the operative treatment of cataract is a subject of never-ceasing interest. In the East, and particularly in India, it forms, to many surgeons, qualified and unqualified, specialist and not, all or most of ophthalmology. Much has been, and will continue to be, written on the subject so long as it retains a place in ophthalmic surgery. The observations set down by the contributor of this article have been made independently by him, but he does not lay claim to anything new. $\mathrm{He}$ well remembers seeing the collection of accouchement instruments excavated from the ruins of Pompeii which strikingly resemble those in use to-day. It would seem that the trite saying, "There is nothing new under the Sun," is none the less true.

He was greatly impressed by watching the work of Col. Smith at Amritsar in 1920. In 1930 when he began work as an eyespecialist at Madura he intended to work on the lines of Smith. But, not having a trained staff nor control over it, had to give up intra-capsular extraction and fall back on the capsulotomy operation. Towards the middle of 1932 so many cases returned for needling that it became a matter of serious concern to avoid a second operation and he decided to try the intra-capsular method again. By this time the staff had come under his direction. From then on he has almost exclusively performed intra-capsular extraction. It would be better, perhaps, to say "Expression," because the lens is made to come out by graduated pressure.

The method adopted by the writer, however, differs so greatly from that of Smith that it would be better to set down the details.

\section{Smith's Operation}

Smith's operation in brief:-Corneal section, full and fairly wide iridectomy and expression of the lens. Smith used to say that a brisk reacting pupil was sufficient indication of a healthy retina behind and he used to carry out no further test, but simply take the cases on to the operating table as they came from their homes. 
The writer has followed the orthodox methods of preliminary observation, investigation and treatment of the cases as far as practicable within the limitations of the institution in which he worked. He has noticed in some cases showing a quick reaction of the pupil to light, that the projection was poor and consequently the result of operation unsatisfactory.

\section{Author's Operation}

The present writer's method:-The lacrymal passages are tested for patency and syringed out the day previous to the operation. Eyebrows are shaved and eyelashes cut; a clean shave of the face also whenever necessary.

Anaesthesia.-In practically all the cases pantocain was the anaesthetic used; a 1 in 200 solution for instillation, 1 in 500 for the facial block and 1 in 400 for the ciliary block. The anaesthesia was almost invariably successful.

Details of the Operation. $-1 \frac{1}{2}$ to 2 hours previously the eye is washed out with $1: 3000$ corrosive sublimate lotion and a drop of 2 per cent. homatropine and cocaine solution instilled. The face is then painted with tincture of iodine or picric acid. At operaation, four instillations of the anaesthetic solution are made at two minute intervals, a drop of fresh 1 in 1000 adrenalin being instilled along with the anaesthetic at the second and third instillations. The facial nerve is blocked at the neck of the mandible and the ciliary block done through the lid at the inferotemporal angle of the orbit. The eye is then well washed out with sterilised normal saline. Speculum is introduced and section, a little smaller than hemi-, is made through the corneo-scleral junction and a conjunctival flap is formed. The flap is turned down on the cornea. The assistant then raises the speculum off the globe. The iris is seized close to its root with straight iris forceps and a small knuckle of iris is gently brought out of the wound and a radial incision is made to one side of the tip of the forceps. The iris is then carefully replaced.

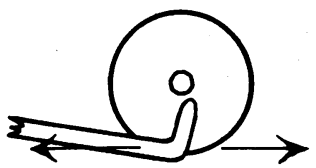

FIG. 1.

To illustrate the stroking movement.

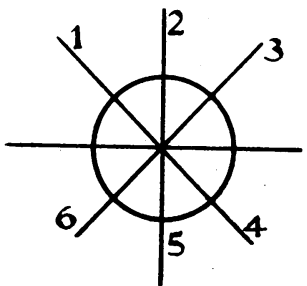

FIG. 2.

The various " presentations." 
With the strabismus hook placed on the lower part of the cornea gentle pressure is exerted towards the lower pole of the lens and at the same time the bend of the hook is stroked to and fro along the lower limbus. Under this combined pressure and kneading movement the zonule gives way at its weakest spot, which differs in different eyes. The writer has noticed it giving way at any of the 6 points shown in the diagram, as evidenced by the lens beginning to bulge out at the spot. The stroking part of the manoeuvre is now stopped and the pressure alone is continued. The lens slowly expands the pupil and comes out through it and then out of the section. In the positions above the horizontal diameter it comes out straight and in those below as a "tumbler." Depending on the consistency of the lens it takes on a characteristic
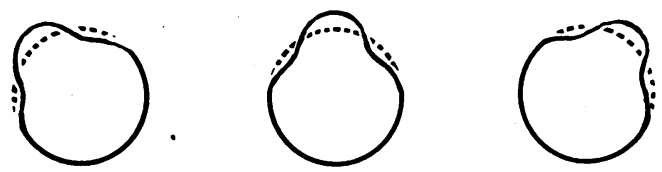

FIG. 3.

Lens moulding. Interrupted line shows outline of un-moulded lens.

moulding as does the foetal head coming out of the pelvis. The iris usually remains in place after the delivery of the lens because of the contraction of the pupil. If not it is carefully replaced. The conjunctival flap is stroked back into position, a drop of eserine or atropine solution instilled and a small quantity of a carefully sterilised ointment of the same is introduced to glue the lid margins together and the two eyes are bandaged.

The bandage is opened on the third morning and the eye is examined. If everything is satisfactory the operated eye alone is bandaged. Dressings are discarded on the eighth day.

This is a brief description of the operation. The complications at and after the operation are the usual ones described in text-books and need not detain us. Sometimes haemorrhage from an internal pterygium can be avoided by making the section oblique temporalwards.

Prolapse and actual loss of vitreous are the complications which have been the objections against this type of operation. The writer believes that if what follows is carefully studied these complications will not be considered so formidable.

As in every operation the suitability of the case for operative treatment is a great point. Firstly cataracts, from the operative point of view, can be classed into immature, mature and hypermature. The pros and cons of the advisability of operating on 
immature cataracts need not be entered into here. Each case has to be decided on its merits. For the type of operation described in this article the cataract that is just mature is the best suited. For, it is in this that the cortex is soft and capable of the degree of moulding that is required of it to come successfully out of the pupil and then the section. The immature, on account of the healthy lens fibres still present, is too tough easily to mould itself.

Of the hypermature the black type is very difficult to deliver because it is all nucleus and does not mould well. But the other, the Morgagnian, is far and away the most difficult of all for this type of operation. In the report of the Madras Government Ophthalmic Hospital for the year 1931 it is stated: " it (intra-

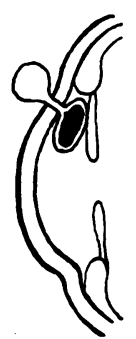

FIG. 4

Nucleus of Morgagnian cataract lying across section.

capsular operation) is eminently suitable for Morgagnian cataract." In the writer's experience it is not so. The nucleus of the Morgagnian cataract, in the operation described above, behaves like the after-coming head in a breech case. The bag of fluid easily pushes its way through the pupil and is followed by the nucleus because it is a round aperture; but the fluid makes the section only just gape and passes through and the after-coming nucleus hitches against the sides of the slit like the base of a collar stud below the button-hole, and makes it extremely hard to get it out. This has occurred many a time in the writer's experience. In one case the lens executed a triple somersault in the anterior chamber before coming out of the eye.

Secondly, the appearance of the eye itself on completion of the section is an indication of its suitability or otherwise. The writer has observed that the eye behaves in one of three ways; there are those in which the cornea collapses backwards; there is a second class in which the cornea retains its shape and the iridolenticular diaphragm remains in its normal position; and there 
is the third group in which the cornea not only retains its shape but the irido-lenticular diaphragm moves forward. If this phenomenon is not manifest immediately the knife is out of the section it becomes so on the assistant raising the speculum.

This no doubt indicates the tissue tension and the tension of the eye-ball. But it has got the greatest bearing on the operation. The first two classes are the ones in which an intra-capsular operation can be done with perfect safety by anybody. The last is the class in which sometimes, even with capsulotomy, escape of vitreous occurs. That is, perhaps, the reason why this complication finds its mention even in books which advocate only the capsulotomy operation.

Even in this class of eyes intra-capsular operation can be attempted by one alive to the possibility of vitreous trouble. If a careful watch is kept on the emerging rim of the lens and a black bead is noticed behind the rim of the lens, pressure of the hook is immediately slackened, a vectis passed behind the lens and a quick delivery effected, there can be no loss of vitreous. At the most there is a tiny amount clinging to the ring of the vectis. The iris being entire keeps the vitreous effectively back from the section.

Complicated cataracts, in the accepted sense, are treated according to the conditions obtaining in the individual case. But there are two types which may be noted here. There is the cataract developing in an eye which has previously had a trephining done for chronic glaucoma. It has been the writer's experience that trephining is a very unsatisfactory operation from the point of view of a later cataract extraction. The larger opening made for the latter acts much more effectively for filtration, during the days immediately following the operation and so the filtering scar closes up. At the end of the week the section also is healed and when the bandage is discarded it is found that little vision is left in the eye. This has happened several times in the writer's practice. With an iridencleisis this does not appear to occur ; but the writer's experience is not large. He has had only one case, in which the iridencleisis was performed at another hospital and cataract was successfully removed by him through a section placed a little anterior to the iris inclusion with good results.

When cataract develops in an eye which has a congenital coloboma, infero-nasal, the usual position, whatever the method of operation it is very difficult to bring the lens out and the result of operation is disappointing. The writer has had two cases of this kind in his practice. Operation was undertaken because this was the only functioning eye before the development of cataract and curiously enough both were left eyes. In the first the usual section was made. The lens nucleus moved up and remained 
hitched against the upper lip of the section and was removed with the vectis under the most difficult conditions. Thinking that the defect in the zonule below was the cause of this difficulty the section was made below in the second case. It did not in any way facilitate extraction.

This article has been written to invite the attention of ophthalmic surgeons to a type of the intra-capsular operation which may be adopted more universally. If suitability and the behaviour of the eye on section are well weighed and the operation conducted with ordinary care and patience the results are almost uniformly good. A large proportion of the writer's cases have been discharged with perfectly round jet-black pupils, like those of babies.

In the Madras Report referred to above Wright derides the " boat-shaped " pupil that is said, sometimes, to result after this operation. But such a pupil is seen only if there is a loss of vitreous and some incarceration has taken place in the section. If the pressure is modulated and time is allowed for the lens to mould through the pupil this does not occur. Pulling out the lens by a forceps gripping its anterior capsule or an erisiphake clinging to it is in the nature of a " vis a fronte," lifting the lens bodily at once from the fossa patellaris, with the creation of a potential vacuum in the latter which can only be filled by a displacement of the vitreous. In these a boat-shaped pupil is more likely to result.

With an uncut iris the difficulty is to overcome the sphincter and the all-important factor here is a modulated steady pressure. One is often tempted to release the presenting rim of the lens from the grip of the pupil, as this is the stage at which delay occurs, by counter-pressure with an iris repositor. But this is undesirable and will lead to distortion of the pupil. In fact the use of two instruments for the delivery of the lens except in case of vectis delivery is simply inviting disaster. The time taken to overcome the pupillary sphincter varies in different cases, being just a few seconds in some and many minutes in others.

Another objection to this kind of operation is the likelihood of opacity of the cornea developing as a result of the pressure of the hook. Unless the epithelium of the cornea is denuded by a too free use of cocaine this does not occur. When it takes time for the lens to mould all that is necessary to prevent injury to the cornea is to keep it moist with normal saline lotion.

Out of an experience of more than 1,500 cataract operations the number under review is 629 . The tables which follow give details culled from the case sheets of all the cases from the time of commencement of this type of operation at the end of June, 1932, to the end of 1933. The cases have not been specially selected; 
"the fat and the lean" are all included. Owing to the practice, subsequently changed, of noting visions on outpatient tickets, which are not now available to the writer, on the discharge of the patients from the wards, 289 case sheets do not show a record of vision after operation.

As regards vision it should be remembered that almost all the cases operated on belong to the South Indian villager class, a class proverbially ill-nourished and half-starved, lacking the articles of diet containing vitamins from year end to year end. It is worth mentioning here that many students drawn from this class have attended the clinic for defective vision in whom an exhaustive examination had failed to reveal any error of refraction or other abnormality whose vision improved on the administration of cod liver oil. In the relatively small number of better class cases operated on at hospital and in private cases the vision with correction has been $6 / 6$ or better and Jaeger 1 .

Secondly, many have such a rooted objection to wearing glasses that they refuse the free gift of suitable correction at Government expense, simply expressing contentment at the "lifting of the curtain before their eyes" as they quaintly put it.

\begin{tabular}{c|c|c|c|c|c}
\multicolumn{5}{c}{ TABLE I } \\
\cline { 2 - 5 } Total & Immature* & Mature & Black & Morgagnian & Complicated \\
\hline 629 & 109 & 462 & 1 & 36 & 21 \\
\hline
\end{tabular}

* Vision ranging from fingers close to the face to less than half metre in most, only a few counting fingers beyond half metre.

Note.-28 were "Tumblers" including 9 Morgagnians.

TABLE II

\begin{tabular}{c|c|c|c|c|c}
\hline Total & V. recorded & $\begin{array}{c}\text { V.not } \\
\text { recorded }\end{array}$ & Sepsis & $\begin{array}{c}\text { Internal } \\
\text { Haemorrhage }\end{array}$ & Died \\
\hline 629 & 331 & 289 & 4 & 2 & 3 \\
\hline
\end{tabular}

TABLE III

\begin{tabular}{c|c|c|c|c}
\hline $\begin{array}{c}\text { Vectis } \\
\text { delivery }\end{array}$ & $\begin{array}{c}\text { Vitreous } \\
\text { threatened } \\
\text { and receded }\end{array}$ & Vectis & No vectis & $\begin{array}{c}\text { Lens sank } \\
\text { back }\end{array}$ \\
\cline { 3 - 5 } 47 & 12 & 14 & 20 & 1 \\
\hline
\end{tabular}


TABLE IV

\begin{tabular}{l|c|c}
\hline & Total & Vitreous loss* \\
\hline $\begin{array}{l}\text { Intra-capsular including } \\
\text { vectis delivery }\end{array}$ & 580 & 32 \\
Capsulotomy - - & 49 & 2 \\
\hline
\end{tabular}

* No attempt has been made to classify into "One bead," etc., as the writer believes the seriousness is the same whether the loss is small or great.

TABLE V

Prolapse Ratio

\begin{tabular}{l|c|c|c|c}
\hline & Simple & Iris slit & $\begin{array}{c}\text { Buttonhole } \\
\text { iridectomy }\end{array}$ & $\begin{array}{c}\text { Full } \\
\text { iridectomy }\end{array}$ \\
\hline Total of each - & 20 & 373 & 18 & 218 \\
No. of prolapses & 1 & 15 & 0 & 6 \\
\hline
\end{tabular}

TABLE VI

Vision uncorrected

\begin{tabular}{|c|c|c|c|c|c|c|c|}
\hline $\begin{array}{l}\text { Nature of } \\
\text { operation }\end{array}$ & & $\mathrm{V}=0^{*}$ & $\begin{array}{l}\mathrm{V}=\mathrm{F} . \mathrm{be}- \\
\text { low } \frac{1}{2} \mathrm{~m} .\end{array}$ & $\begin{array}{c}\mathrm{V}=\mathrm{F} \\
\frac{1}{2} \text { to } 1 \mathrm{~m} .\end{array}$ & $\begin{array}{c}\mathrm{V}=\mathrm{F} . \\
1 \frac{1}{2}-2 \mathrm{~m} .\end{array}$ & $\begin{array}{c}\mathrm{V}=\mathrm{F} \\
\text { over } 2 \mathrm{~m} .\end{array}$ & \\
\hline Capsulotomy & - & 3 & 8 & 12 & 1 & 0 & 49 \\
\hline Capsule burst & - & 1 & 3 & 10 & 0 & 0 & 33 \\
\hline Intra-capsular & - & 1 & 40 & 184 & 17 & 1 & 547 \\
\hline Vectis delivery & $\cdot$ & 1 & 4 & 15 & 0 & 0 & \\
\hline Vitreous loss & - & 4 & 3 & 10 & 0 & 0 & \\
\hline Complicated & - & 12 & 0 & 0 & 0 & 0 & \\
\hline Lens sank back & - & 0 & 1 & 0 & 0 & 0 & \\
\hline
\end{tabular}

* Includes perception of light and hand movements also.

\section{Summary}

1. Intra-capsular expression of cataract of the type described above is a safe and simple operation and gives excellent results.

2 . Suitability of the case depends on the degree of maturity of the cataract and the behaviour of the eye on section, the first two groups being the most suitable.

3. It reduces intra-ocular instrumentation to the lowest and does not require elaborate and costly apparatus.

4. It avoids the risks of a second operation. 
5. Bad results like "boat-shaped" pupil can be avoided by taking as much time as necessary for the moulding of the lens to occur.

6. Traumatic opacification of the cornea does not occur if cocaine is not used too freely and the cornea is kept moist.

7. It reduces the period of hospitalisation. Patients can be discharged from the hospital at the end of a week and in many cases all the reaction of the operation subsides in a fortnight and the eye is white.

\title{
TRANSPLANTATIO CONCHAE AURICULAE AS A NEW METHOD OF CORRECTING SPASTIC ENTROPION OF THE UPPER LID FOLLOWING TOTAL TARSECTOMY*
}

BY

\author{
N. I. SHIMKIN \\ HAIFA, PALESTINE
}

IN 1928, at a sitting of the Ophthalmic Section of the International Congress of Tropical Medicine and Hygiene in Cairo, Egypt, I read a paper entitled "Three cases of Spastic Entropion post tarsectomia totalis of the upper lid, cured by Homoplastica tarsi " (published also in Klin. Monatsbl. f. Augenheilk., Maerz, 1929, S.360-364). I had the opportunity of observing the cases from six to seven years after the operation. In all cases the lid had kept its normal position so that the proposed method of homoplastica tarsi in spastic entropion post tarsectomia totalis has affected its purpose.

But the method "homoplastica tarsi" in suitable cases of spastic entropion has the disadvantage that there is not always material suitable for plastic operation available. When there is a patient with spastic entropion following total tarsectomy, there may be no patient needing tarsectomy whose tarsus could be used for transplantation, and vice versa.

In order to overcome this inconvenience, I decided to make use of the concha auriculae, as a plastic material. The fact that the auricular cartilage is a good plastic material, is mentioned in all manuals of ophthalmic surgery. Buedlinger and Muller's operation for correcting the defects of the eye lid by means of auricular cartilage, has come into general use.

* Paper read on December 10, 1937, in the Assembly of Delegates at the International Organisation against Trachoma. Fifteenth Congress of Ophthalmology, Cairo, Egypt. 